\title{
Review
}

\section{Review on Epidemiology and Economic Impact of Small Ruminant Brucellosis in Ethiopian Perspective}

\author{
Mohammed Mustefa, DVM*; Beredo Bedore, DVM \\ College of Veterinary Medicine, Haramaya University, P. O. BOX 30I, Haramaya, Ethiopia \\ *Corresponding author \\ Mohammed Mustefa, DVM \\ College of Veterinary Medicine, Haramaya University, P. O. Box 30I, Haramaya, Ethiopia;Tel.+2519166784I2; E-mail: beredobedoreg@yahoo.com
}

\section{Article information}

Received: June $6^{\text {th }}, 2019$; Revised: October 29 ${ }^{\text {th }}, 2019$; Accepted: November $7^{\text {th }}, 2019$; Published: November $30^{\text {th }}, 2019$

\section{Cite this article}

Mustefa M, Bedore B. Review on epidemiology and economic impact of small ruminant brucellosis in Ethiopian perspective. Vet Med Open J. 2019; 4(2): 77-86. doi: 10.17I40/VMOJ-4-139

\section{ABSTRACT |}

Brucella are intracellular bacteria that cause brucellosis, a chronic zoonotic disease. The genus of Brucella are subdivided into six species categorized by antigenic variation and primary preferred host and these include B. abortus, B. melitensis, B. suis, B. ovis, B. canis and $B$. neotomae. The epidemiologies of the disease in livestock and humans, as well as appropriate preventive measures, are not well understood in developing countries. Materials excreted from the female genital tract acting as the main supply of organisms for transmission to other animals and human. Millions of individuals are at risk worldwide, especially in countries where infection in animals has not been brought under control, procedures for the heat treatment of milk, such as pasteurization are not routinely applied, and standards of hygiene in animal husbandry are low. A precise diagnosis of brucellosis is important for the control of the disease in animals and consequently in human. Molecular and serological techniques are important tools for diagnosis and epidemiologic studies, providing relevant information for identification of species and biotyping. The economic and public health impact of bucellosis remains particular concern and neglected in developing countries. The disease mainly hampers the productivity of small ruminant's resulting infertility and increase the average inter-calving periods. One of the major gaps in our knowledge at present is the relative contribution of brucellosis on small ruminant and humans. In Ethiopia, no strategy is in place to control brucellosis. The most important approach to the control and prevent human of brucellosis in human and animal is the practice of one health approach. So knowing the status of small ruminant brucellosis in our country is therefore extremely important. Therefore, the aims of this review are; a) To highlight (snapshot) of brucellosis in the small ruminant; b) To show the seroprevalence status of small ruminant brucellosis in Ethiopia perspective; c)To highlight possible risk factor and its economic importance.

\section{Keywords}

Small ruminants; Brucellosis; Sheeps; Goats, Ethiopia.

\section{Abbereviations}

ASS: Agricultural Sample Survey; CFSPH: Center for Food Security and Public Health; CFT: Complement Fixation Test; CSA: Central Statistical Agency of Ethiopia; ELISA: Enzyme Linked Immuno-Sorbent Assay; FAO: Food and Agricultural Organization; IBM: Interim Brucellosis Manual; Ig: Immunoglobulin; ILCA: International Livestock Center for Africa; MoARD: Ministry of Agriculture and Rural Development; MZN: Modified Ziehl-Neelsen; NVI: National Veterinary Institute; OIE: Office International de Epizootics; RBPT: Rose Bengal Plate Test; WHO: World Health Organization; I-ELISA: Indirect Enzyme Linked Immunosorbent Assay.
\end{abstract}

\section{INTRODUCTION}

L ivestock plays a crucial role in the livelihoods of the majority of Africans. It accounts for $16 \%$ of the national and $27-30 \%$ of the agricultural gross domestic products (GDPs) and 13\% of the country's export earnings. The greatest share of this income is from small ruminants. ${ }^{1}$ According to the animal population survey results conducted at rural sedentary areas at country level in 2016/17, the estimates livestock of cattle to be about 59.5 million, about 30.70 million sheep, about 30.20 million goats, about 2.16 million horses, about 8.44 million donkeys, about 0.41 million mules, and about 1.21 million camels and poultry population ${ }^{2}$ 
about 56.53 in Ethiopia. According to statistics from the Central Statistical Agency (CSA), ${ }^{3} 25 \%$ of the sheep and $73 \%$ of the national goat population inhabit in the lowlands.

Small ruminants are among important domestic animals which are highly adaptable to a broad range of environmental conditions ${ }^{4}$ and they fulfill a number of economic and social functions. Unlike a large number of small ruminant's populations, the country fails to optimally utilize these resources mainly various factors in which diseases stand front line. One of the diseases that hamper the productivity of small ruminant is bucellosis. ${ }^{5}$

The economic and public health impact of bucellosis remains of particular concern in developing countries. ${ }^{6}$ The disease can affect almost all domestic species and cross transmission can occur between cattle, sheep, goat, camel and other species. ${ }^{7,8} \mathrm{Sev}$ eral closely related species of the genus Brucella have been recognized, namely B. abortus, B. melitensis, B. suis, B. ovis, B. canis, B. neotomae, B. pinnipedialis, B.ceti, B. microti, and B. inopinata ${ }^{9}$ and small ruminants infected by ingestion of contaminated feed or water and the consequences of the infection are determined by the virulence of the bacteria, resistance and reproductive status of the host. ${ }^{10} \mathrm{In}$ animals, abortion is typically one of the clinical signs of pregnant females, and orchitis and epididymitis are typical clinical signs of the male. Excretion of the organisms in uterine discharges and in milk is common. ${ }^{11}$

Brucellosis is considered as neglected zoonotic disease by the World Health Organization (WHO) and has been identified as having the highest public health burden across all sections of the community. Millions of individuals are at risk worldwide, especially in countries where infection in animals has not been brought under control and standards of hygiene in animal husbandry are low. ${ }^{12}$ Materials excreted from the female genital tract are the main supply of organisms for transmission to other animals and man. ${ }^{13}$ The disease is transmitted to man mainly by direct contact with infected livestock or through consumption of raw or uncooked animal products. ${ }^{14}$ B. melitensis (biovars 1, 2 or 3 ) is the main causative agent of caprine and ovine brucellosis and it is highly pathogenic for humans causing udulant or Malta fever followed by B. suis, B. abortus and B. canis in human. ${ }^{15}$

The epidemiology of the brucellosis livestock and humans as well as appropriate preventive measures is not well understood, and in particular, such information is inadequate in developing countries of Sub-Sahara, including Ethiopia. ${ }^{16,17}$ The disease spreads from one herd to another and from one area to another is always due to the movement of infected animals. Hence, lack of biosecurity measures such as strict movement control of animal from one area to another, lack of proper hygienic practices and good husbandry management play a great role in the increment of the prevalence of brucellosis. ${ }^{18,19}$

The control and prevention of brucellosis in farm animals depend on animal species involved, B. Spp. management practices and availability and efficacy of vaccines. The options to control the disease include immunization, testing and removal, and improving management practices and movement control. ${ }^{20} \mathrm{~A}$ very important approach to the control of brucellosis that is gaining more and more recognition around the world in recent years is the one health approach to control and prevent human and animal brucellosis. $^{\text {? }}$

\section{LITERATURE REVIEW}

\section{Description of the Agent}

Definition and etiology: Brucellosis in small ruminants is mainly caused by B. melitensis and B. ovis and in sporadic cases B. abortus. B. melitensis is most commonly infects sheep and goats. Breed susceptibility is variable in sheep, but goat breeds are highly susceptible. B. ovis primarily affects rams ${ }^{21}$ and important cause of orchitis and epididymitis in rams and occasionally infects ewes. ${ }^{22}$

Brucellosis is a contagious bacterial disease of an animal which has zoonotic importance, causing significant reproductive losses in animals. ${ }^{23-25}$ The genus of Brucella are subdivided into six species categorized by antigenic variation and primary preferred host and these include B. abortus, B. melitensis, B. suis, B. ovis, B. canis and B. neotomae. ${ }^{26}$

Brucellae are intracellular, coccobacilli or short rods, usually arranged singly but sometimes in pairs or small groups. The organisms are gram-negative facultative intracellular parasites. ${ }^{23}$ Carbon dioxide is important elements for the growth of Brucella organism, especially $B$. abortus; such organisms, which require carbon dioxide for their growth, are called capnophilic organisms. At $\mathrm{pH}<4$, Brucella agents do not have the potential to survive. ${ }^{27}$

\section{Epidemiology}

Geographical distribution: Brucellosis is a highly worldwide contagious bacterial disease affecting both animal and human. ${ }^{28}$ Remains endemic among Mediterranean countries of Europe, Northern and Eastern Africa, near East countries, India, Central Asia, Mexico and Central and South America. ${ }^{29}$ B. melitensis is considered to be a re-emerging pathogen in the Middle East ${ }^{30}$; where there is an increasing incidence of $B$. melitensis or B. suis biovar 1 infection in cattle. $^{28}$

Among the members of the Brucella group B. abortus, $B$. melitensis and B. suis species are not host-specific, and may transmit to other animal species; hence, from epidemiological evidence, the three species (B. abortus, B. melitensis, and B. suis) have distinct host preferences and the organisms are capable to cause an infection in a wide range of host species, including humans. The remaining three members of the species have much greater host specificity. Cross transmission of brucellosis can occur among cattle, swine, sheep and goats and other species including dogs, horses, feral swine, bison, reindeer and camels. ${ }^{29}$

The lack of vaccines for humans will continue to make this disease a global health threat. The lack of a human brucellosis vaccine remains challenging due to the risk of Brucella as a pos- 
sible bioweapon agent, and because brucellosis remains a global health problem affecting at least a half million people annually. ${ }^{31}$ Even for the most common if the most prevalent brucella Spp. of human is $B$. melitensis there is no vaccine provided so far. ${ }^{32-34}$

Source of infection and mode of transmission: Materials excreted from the female genital tract forming the main supply of organisms for transmission to other animals and man. Therefore, in most circumstances, the primary route of dissemination of Brucella is the placenta, fetal fluids and vaginal discharges expelled by infected ewes after abortion or full-term parturition. Very large numbers of organisms are shed at the time of parturition or abortion. ${ }^{35}$

Horizontal transmission occurs through ingestion of contaminated feed, skin penetration, via conjunctiva, inhalation and udder contamination during milking or by licking the discharge of an animal, newborn calf or retained fetal membrane. ${ }^{36}$ Venereal infections can also occur and mainly infected with B. suis infections. The importance of venereal transmission varies with the species; it is the primary route of transmission for B. ovis, B. suis and $B$. canis frequently by this route. $B$. abortus and B. melitensis can be found in semen, but the venereal transmission of these organisms is uncommon. ${ }^{10}$

B. melitensis frequently occurs in sheep and goats and is highly pathogenic for humans, causing as it does one of the most serious zoonoses in the world. ${ }^{29,35}$ The disease is responsible for considerable economic losses to the small-ruminant industry. ${ }^{13}$

In human, brucellosis is spread through contact with blood, body tissues, or body fluids of infected animals. The most common method is the consumption of unpasteurized milk and dairy products. Human infections may occur through breaks in the skin when handling infected animal tissues. ${ }^{31}$ In the laboratory and probably in abattoirs, Brucella can be transmitted through aerosols; contact with laboratory cultures and tissue samples; and accidental injection of live Brucella vaccines. ${ }^{37}$

Possible risk factors: Agent factors: Brucella is intracellular pathogen which is able to survive and replicate within phagocytic cells. It can persist on fetal tissues and soil or vegetation for 21-81-days depending on the month, temperature, and exposure to sunlight. B. abortus field strain persisted up to 43-days in oil and vegetation at naturally contaminated bison birth or abortion sites. ${ }^{5}$

The organisms are able to survive within host leukocytes and may utilize both neutrophils and macrophages for protection from humoral and cellular bactericidal mechanism during the period of haematogenous spread. The inability of the leukocytes to effectively kill virulent $B$. abortus at the primary site of infection is a key factor in the dissemination to regional lymph nodes and other sites such as recticuloendothelial system and organs such as the uterus and udder. ${ }^{36}$ The congregation of a large number of mixed ruminants at water points facilitates disease spread. ${ }^{11}$

Host factor: Population density (number of animals to land area) is attributed to increased contact between susceptible and infected animals. Health status of the animals may also play a great role in acquiring and spread of the disease infection. Vaccinated and disease free animals are less susceptible than unvaccinated and immune compromised diseased animals. ${ }^{11}$ Goats are at higher risk of acquiring Brucella infection than sheep. This may be due to the greater susceptibility of goats to Brucella infection. It could also be partly due to the fact that goats excrete the organism for a long period of time, unlike sheep. ${ }^{36}$

The receptivity of ewes to $B$. melitensis varies according to the breed. Milk producing ewes are more receptive than sheep feed lot sheep. ${ }^{33}$ Sexually mature and pregnant animals are more prone to brucellosis than sexually immature animals of either sex..$^{36,38}$

Brucellosis sero-prevalence increased with age and sexual maturity. The antibody titer against $S p p$. appears to be associated with age, as a low prevalence in young stock has been reported than the adults. ${ }^{39-42}$ This low prevalence in young animals may be explained on the basis that the animal may harbor the organism without expressing any detectable antibodies until their first parturition or abortion. It may be possible that after entry, the organism localizes itself in the regional lymph nodes and enjoy there without provoking antibody production until the animal is conceived and start secreting erythritol, which stimulates and supports the growth of Brucella organisms. ${ }^{43-46}$ This is related to the fact that sex hormones and meso-erythritol (in male testicles and seminal vesicles) and erythritol in female, allantoic fluid stimulate the growth and multiplication of Brucella organisms and tend to increase in concentration with age and sexual maturity. ${ }^{11,47,48}$

Reservoir: Carrier animals facilitate the transmission of brucellosis highly by contaminating the environment and also being the site of multiplication for the Brucella organisms in their body and excreting such agents and again the execrated organisms infect animals and humans then bring hazards on health and economy of the country. The carriers are dogs, cats and wild carnivores, such as foxes and wolves, which may be important as mechanical disseminators of infection by carrying away infected material such as fetuses or fetal membranes enhances the viability of the organisms in the environment, thus increasing the chances of infecting susceptible animals. $^{29}$

\section{Environmental and Climatic Factors}

The survival of the organism in the environment plays a great role in the epidemiology of the disease. ${ }^{17}$

Brucella may retain infectivity for several months in water, aborted fetuses and fetal membranes, feces and liquid manure, wool, hay, on buildings, equipment and clothes. Brucella is also able to withstand drying particularly in the presence of extraneous organic material and will remain viable in dust and soil. ${ }^{21}$ Temperature, humidity and $\mathrm{pH}$ influence the organism's ability to survive in the environment. Brucella is sensitive to direct sunlight, disinfectant and pasteurization. ${ }^{11}$ 
Management: The spread of the disease from one herd to another and from one area to another is always due to the movement of infected animals from an infected herd into a non-infected susceptible herd. Hence, lack of strict movement control of animal from one area to another, lack of proper hygienic practices and good husbandry management play a great role in the increment of the prevalence of brucellosis. ${ }^{18}$

Occupations at higher risk: People who work with animals or come into contact with infected blood are at higher risk of brucellosis. Examples include: veterinarians, dairy farmers, ranchers, slaughterhouse workers, hunters, microbiologists and farmer ${ }^{7}$ and also those handling artificial insemination, abattoir and slaughterhouse personnel working in endemic areas are at risk. Brucellae are considered as potential bioweapons. ${ }^{5}$

\section{Pathogenesis}

B. melitensis can enter mammalian hosts through skin abrasions or cuts, the conjunctiva, the respiratory tract, the gastrointestinal tract and through reproductive tracts. In the alimentary tract the epithelium covering the ileal Peyer's patches are preferred site for entry. In the gastrointestinal tract, the organisms are phagocytosed by lymphoepithelial cells of gut-associated lymphoid tissue, from which they gain access to the sub-mucosa and localized to the reticulo-endothelial system and genital organs. ${ }^{49}$

The initiation of Brucella infection depends on exposure dose, the virulence of the $B$. Spp. and natural resistance of the animal to the organisms. ${ }^{36}$ They are taken up in phagosomes, remain viable by suppressing phagosome-lysosome fusion, and inhibit apoptosis of host cells. They multiply in vacuoles within the endoplasmic reticulum and from there spread to various organs, particularly into the cells of the reticuloendothelial system, liver, spleen, skeletal muscle, and urogenital tract where they give rise to granulocytic inflammation with or without necrosis or caseations. ${ }^{5}$

After the Brucella organisms spread through the hematogenous route in females then also reaches the placenta and finally to the fetus. The preferential localization to the reproductive tract of the pregnant animal is due to the presence of the allantoic fluid factors that would stimulate the growth of Brucella. Erythritol (four-carbon alcohol) is considered to be one of the factors, which are elevated in the placenta and fetal fluid from about the fifth month of gestation. An initial localization within erythrophagostic trophoblasts of the placentome adjacent to chorioallantoic membrane results in rupture of the cells and ulceration of the membrane. The damage to placental tissue together with fetal infection and fetal stress inducing maternal hormonal changes may cause abortion. ${ }^{36}$

\section{Clinical Feature of Small Ruminant Brucellosis}

Disease in animal: In animals, brucellosis can be latent for several years. In females, it manifests itself as abortion, neonatal weakness, retention of the placenta, endometritis and, rarely, mastitis.
In males, orchitis, epididymitis and subsequent infertility. In cattle and other animals, polyarthirits, tendovaginitis, and bursitis have been observed. ${ }^{5}$ This disease has no pathognomonic lesions leathery placenta and the changes that can be observed are necrotizing placentitis, palpable testicular alterations, necrotizing orchitis and epididymitis with subsequent granuloma, necrotizing seminal vesiculitis and prostatitis. Some aborted fetuses may have an excess of blood-stained fluids in the body cavities, with enlarged spleen and liver. Others appear normal. Infected fetal membranes show changes affecting part or all of the membrane. The necrotic cotyledons lose their blood-red appearance becoming thickened and dull-grey in color. In the chronic stage of the disease, the epididymis can be increased in size up to four or fivefold. ${ }^{50}$

Disease in human: Brucellosis, a foodborne zoonosis has caused considerable morbidity in humans in many parts of the world with major impacts on young children and elderly people. The two species: B. melitensis and B. suis have been reported to be more virulent in humans. ${ }^{30}$

Human brucellosis is characterized by a variable incubation period (from several days up to several months), and clinical signs include symptoms of continued, intermittent or irregular fever of variable duration, with headaches, weakness, profuse sweating, chills, depression and weight loss. Localized suppurative infections may also occur. Abortion has also happened during the early trimesters of pregnancy. ${ }^{29}$ In the chronic form, it may result in serious complications in which the musculoskeletal, cardiovascular and central nervous systems are affected. ${ }^{51}$

\section{Diagnosis}

A precise diagnosis of brucellosis is important for the control of the disease in animals and consequently in human. Clinical diagnosis is based usually on the history of reproductive failures in livestock, but it is a presumptive diagnosis that must be confirmed by laboratory methods. ${ }^{52}$

Both in humans and animals, clinically diagnosing of brucellosis is not easily achieved because of the presence of other diseases which have similar clinical signs. Even if clinical history and information about the patient give some clue in humans case, laboratory tests such as screening tests and confirmatory tests are very important tools for a correct identification of the disease in humans and for the detection and confirmation in animals; this enables to take strategic measures for controlling and prevention of brucellosis both in animals and humans accordingly. ${ }^{27}$

The isolation and identification of Brucella offers a definitive diagnosis of brucellosis. It is useful for epidemiological purposes and to monitor the progress of a vaccination program in animals. ${ }^{29}$ The method of diagnosis includes the following:

\section{Direct Diagnosis}

Microscopic staining: The disease can be confirmed by demonstration of the bacteria in smears. The smears made from vaginal dis- 
charges, placenta, colostrum, fetal stomach fluid or of the aborting cow's lochia, and the abomasum of the aborted fetus using the modified Ziehl-Neelsen (MZN) stain. ${ }^{6,29}$ Impression smears may be taken from freshly cut and blotted tissue surfaces, e.g. cotyledons, by firmly pressing the slide surface against the tissue. Allow to air dry and heat fix smears. In MZN-stained smears, the bacteria appear as red intracellular coccobacilli whereas most other bacteria stain blue. ${ }^{53}$

Bacteriological culture: Isolation of the organism is considered the golden standard diagnostic method for brucellosis since it is specific and allows biotyping of the isolate, which is relevant under an epidemiological point of view. ${ }^{13,54}$ Brucella Spp. is classified as a Biosafety level 3 organism, whose manipulation should be performed in biosafety level-3 laboratories. Importantly, brucellosis is one of the most common accidental laboratory infections, particularly in research laboratories. ${ }^{55}$

All Brucella strains are relatively slow growing, and because the specimens from which isolations best attempted are frequently heavily contaminated, the use of a selective medium, e.g. Farrell's medium is advocated. ${ }^{10}$ Incubation normally continues for 72-hours, but a negative diagnosis can only be made after weeklong incubation. Specimens which may be used for B. abortus isolation include: fetal stomach fluid, spleen, liver, placenta, lochia, milk (especially colostrum or milk within a week of calving), semen and lymph nodes supramammary (chronic and latent infections) and retropharyngeal (early infections) are preferred, but iliac, prescapular and parotid may be used. If serological reactions are thought to be caused by $\mathrm{S} 19$ vaccine strain then it is important to collect prescapular lymph nodes as well. All B. abortus isolates should be forwarded to laboratories capable of biotyping. ${ }^{53}$

B. Spp. colonies are elevated, transparent, convex, with intact borders, smooth, and a brilliant surface. The colonies have a honey color under transmitted light. Optimal temperature for culture is $37^{\circ} \mathrm{C}$, but the organism can grow under temperatures ranging from $20{ }^{\circ} \mathrm{C}$ to $40{ }^{\circ} \mathrm{C}$, whereas optimal $\mathrm{pH}$ ranges from 6.6 to 7.4. Some Brucella spp. requires $\mathrm{CO}_{2}$ for growth. Typical colonies appears 2 to 30 days of incubation, but a culture can only be considered negative when there are no colonies appears 2 to 3 weeks of incubation. ${ }^{56}$

Molecular techniques: Molecular techniques are important tools for diagnosis and epidemiologic studies, providing relevant information for identification of species and biotypes of Brucella spp., allowing differentiation between virulent and vaccine strains. ${ }^{57} \mathrm{Mo}-$ lecular detection of Brucella spp. can be done directly on clinical samples without previous isolation of the organism. In addition, these techniques can be used to complement results obtained from phenotypic tests. ${ }^{54}$

Molecular technologies like, polymerase chain reaction (PCR) is a new approach and applied in many diagnostic works to overcome limitation and difficulties in bacterial culture and serological assays. PCR shows high sensitivity, specificity and overcame the extraneous intervention of mimicry antibodies from sources other than actual infection. ${ }^{36,58}$

PCR and/its variants, based on the amplification of specific genomic sequences of the genus, species or even biotypes of Brucella spp., are the most broadly used molecular technique for brucellosis diagnosis. ${ }^{54}$

Real-time PCR is more rapid and more sensitive than conventional PCR. It does not require post-amplification handling of PCR products, thereby reducing the risk of laboratory contamination and false positive results. Real-time PCR assays have been recently described in order to test Brucella cells. ${ }^{59}$

\section{Indirect Diagnosis}

Detection of antibodies and at a lesser degree the measure of the cell-mediated immunity against relevant Brucella epitopes is the more practical approach. ${ }^{60}$

Serological tests are crucial for laboratory diagnosis of brucellosis since most of the control and eradication programs rely on these methods. Inactivated whole bacteria or purified fractions (i.e., lipopolysaccharide or membrane proteins) are used as antigens for detecting antibodies generated by the host during the infection. Antibodies against smooth Brucella species (e.g., B. abortus, B. melitensis and B. suis) cross reacts with antigen preparations from B. abortus, whereas antibodies against rough Brucella spp. (e.g., B. ovis and $B$. canis) cross react with antigen preparations from B. ovis. ${ }^{61}$

Rose bengal plate test: The rose bengal plate test (RBPT) was used as a screening test for the serum samples collected for the presence of Brucella agglutinins. The test was conducted as per the procedure recommended by OIE and Radostits et al. ${ }^{54,62}$ The interpretation of the results was done according to the degree of agglutination. ${ }^{62}$ Agglutinations were recorded as $0,+,++$ and +++ . A score of 0 indicates the absence of agglutination; + indicates barely visible agglutinations; ++ indicates fine agglutination, and +++ indicates coarse clumping. Those samples with no agglutination (0) were recorded as negative while others were recorded as positive. Positive reactions should be investigated using suitable confirmatory and/or complementary strategies (including the performance of other tests and an epidemiological investigation). ${ }^{53}$

\section{Indirect Enzyme Linked Immunosorbent Assay}

Enzyme linked immunosorbent assay (ELISA) has become popular as a standard assay for the diagnosis of brucellosis, serologically. It measures $\operatorname{IgG}, \operatorname{IgA}$ and $\operatorname{IgM}$ antibodies and this allows a better interpretation of the clinical situation. The diagnosis of brucellosis is based on the detection of antibodies against the smooth Lipopolysaccharides (LPS). Detection of IgG antibodies is more sensitive than detection of $\operatorname{IgM}$ antibodies for diagnosing cases of brucellosis, but specificity is comparable. ${ }^{56,63}$ Enzyme-linked immunosorbent assay (ELISA) is an excellent method for screening large populations for Brucella antibodies and for differentiation between 
any acute and chronic phases of the disease. ${ }^{64}$

Complement fixation test: The complement fixation test (CFT) is the most widely used test for the serological confirmation of brucellosis in animals. The CFT is both sensitive and specific, in the hands of experienced users, and is used as a definitive (confirmatory) blood serum test. ${ }^{53}$ Due to its high accuracy, complement fixation is used as confirmatory test for B. abortus, B. melitensis, and B. ovis infections and it is the reference test recommended by the Organisation for Animal Health (OIE) for international transit of animals. ${ }^{65}$

In most cases, the CFT is used on RBPT positive sera, but like the RBPT, it is also affected to a large extent by the misuse of strain 19 vaccine, particularly when recent or repetitive vaccinations have been used in sexually mature heifers and cows. It is almost impossible to prescribe strict cutoff readings that indicate infection particularly when S19 vaccination reactions play a role due to its misuse. ${ }^{53}$ However, this method has some disadvantages such as high cost, complexity for execution, and requirement for special equipment and trained laboratory personnel. In addition, the test presents limitations with hemolysed serum samples or serum with anti-complement activity of some sera, and the occurrence of prozone phenomena. ${ }^{66}$ Sensitivity of complement fixation ranges from 77.1 to $100 \%$ and its specificity from 65 to $100 \%{ }^{67}$

\section{Management Strategies}

Treatment, control and prevention: The control and prevention of brucellosis in farm animals depend on animal species involved, Brucella spp. management practices and availability and efficacy of vaccines. The options to control the disease include immunization, testing and removal, and improving management practices and movement control. ${ }^{20}$

Small ruminant can get infection from carrier animal's sheep, goat and cattle at pasture and water area. It is the same as those for the control of the disease in populations which are already infected. ${ }^{33}$ Brucellosis can be controlled by test and slaughter policy and vaccination in other livestock. However, developing courtiers cannot afford test and slaughter approach. ${ }^{35}$

There is general agreement that the most successful method for the prevention and control of brucellosis in animals is through vaccination. While the ideal vaccine does not exist, the attenuated strains of B. melitensis strain Rev. 1 for sheep and goats and $B$. abortus strain have proven to be superior to all others. ${ }^{35}$

A very important approach to the control of brucellosis that is gaining more and more recognition around the world in recent years is the one health approach to control and prevent human and animal brucellosis requires multidiscipline efforts since neither veterinarian alone nor physician alone couldn't perform all approaches of control. So it requires the participation of other discipline and farmers for effective control especially in developing countries where most people are live closer to animals.
In Ethiopia at regional levels, no strategy is in place to control brucellosis. ${ }^{68}$ But everybody has own responsibility to keep his environment, animals and own health care. To lower your risk of getting brucellosis from a natural source: Avoid eating or drinking unpasteurized milk, cheese, or ice cream. Check the label to make sure it says "pasteurized" and do not eat it if you aren't sure, do not handle sick or dead animal bodies. But if you must, then use gloves plus face and eye protection, cook meat thoroughly. It is always a good idea to wash your hands regularly and avoid touching your eyes, nose, and mouth and disinfecting of the area where the animals are aborted.

\section{Economic Significance Small Ruminant Brucellosis}

Brucellosis presents a significant impediment to the economic potential of the large population of small ruminants. Since small ruminants and their products are an important export commodity, detaining seropositive animals in quarantine has a negative economic impact. ${ }^{38,69}$

Brucellosis is a major veterinary and human health importance in the economy of affected countries. Among the genus Brucella, B. melitensis, B. abortus, B. suis and B. ovis which preferentially infect sheep and goats, cattle, pigs and sheep, respectively are the most important from a socioeconomic standpoint. In addition to decreasing productivity in animals, the first three species are the main ones responsible for brucellosis in human beings. ${ }^{70}$ Since there is close contact between humans and their livestock, which sometimes share the same housing enclosures, brucellosis is a significant health risk to the entire community. This disease causes acute febrile illness-undulant fever-which may progress to a more chronic form and can also produce serious complications affecting the musculoskeletal, cardiovascular, and central nervous systems (CNS). Brucellosis is a zoonotic bacterial disease caused by Brucella spp. and is primarily a disease of animals, whereas humans are accidental hosts. ${ }^{33}$

Expansion of animal industries, the lack of hygienic measures in animal husbandry and poor food handling partly account for brucellosis to remain a public health hazard. International travel and the importation of different dairy products into Brucella free regions contribute to the ever-increasing concern over human brucellosis. ${ }^{6,29}$ High risk groups include those exposed through occupation in contexts where animal infection occurs, such as slaughterhouse workers, hunters, farmers and veterinarians. ${ }^{29}$

The common sequel of infertility increases the period between lactations in infected herds, and the average inter-calving period may be prolonged by several months. Costs include production loss associated with infection in animals, preventive program, and in the human disease cost of treatment and absenteeism from work brings many economical impacts. ${ }^{36}$

\section{Status of Small Ruminant Brucellosis in Ethiopian Perspective}

In Ethiopia, brucellosis in animals and humans has been reported from different localities of the country, particularly associated with 
cattle in different agro-ecology and production systems. These prevalence studies in animals and human were largely confined to serological surveys and commonly targeted bovine brucellosis, occasionally sheep and goats and rarely camels.

The existing report on seropositivity for small ruminant in different agro-ecology of Ethiopia reveals ranges $1.2-17.4 \%$ for RBPT, and $0.4-13.7 \%$ for CFT. Among few reports on the status of small ruminant brucellosis in Ethiopia, tested sera from 2000 sheep and goats in pastoral regions of Ethiopia and documented $1.9 \%$ positive using RBPT and $1.7 \%$ positive by i-ELISA. Another cross-sectional study conducted on 1568 serum samples from sheep and goats in the pastoral region of Afar revealed $9.37 \%$ positive using RBPT and $4.8 \%$ positive by $\mathrm{CFT}^{49}{ }^{49}$ In $\mathrm{Jijiga}^{71}$ total of serum samples of sheep and 191 from goats) screened 291 serum samples and the result revealed $1.72 \%$ and $1.37 \%$ positivity using RBPT and CFT, respectively. ${ }^{72}$ showed that from a total of 500 serum samples tested, $1.2 \%$ tested positive for brulcellosis infection by the RBPT and only $0.4 \%$ was found positive for CFT. ${ }^{61}$ Revealed that from a total of 840 blood samples (409 sheep and 431 goats) collected all sera samples were screened by modified rose bengal test (mRBT) positive reactors $(4.6 \%)$ were also tested positive in I-IELISA. ${ }^{73}$ Showed that from a total of 1000 serum samples of 388 sheep and 612 goats at an export abattoir tested, $3.7 \%$ tested positive for brulcellosis infection by the RBPT and $2.7 \%$ was found positive for CFT. Central and North East Ethiopia revealed that from a total of 2409 blood samples sheep collected all sera samples screened by mRBT positive reactors $4.9 \%$ and tested positive $4.89 \%$ in CFT. Kombolcha, north east Ethiopia, ${ }^{74}$ a total of serum samples 714 (210 from sheep and 504 from goats) screened samples and the result revealed $2.1 \%$ and $0.7 \%$ positivity

\begin{tabular}{|c|c|c|c|}
\hline \multirow{2}{*}{ Location } & \multicolumn{2}{|c|}{ Prevalence $(95 \%, \mathrm{Cl})$} & \multirow{2}{*}{ Source } \\
\hline & RBPT & CFT & \\
\hline Export Abattoir & 3.4 & 2.7 & 73 \\
\hline Kombolcha, north east Ethiopia & 2.1 & 0.7 & 74 \\
\hline Tellalak district, Afar Region & 17.4 & 13.7 & 75 \\
\hline Mojo and Debreziet export abattoir & 1.99 & 1.76 & 76 \\
\hline Jijiga zone, Somali region & 1.72 & 1.37 & 71 \\
\hline Bahir Dar, North West Ethiopia & 1.2 & 0.4 & 72 \\
\hline Yabellodistricts of Borena Zone & 8.5 & 8.1 (c.ELISA) & 72 \\
\hline $\begin{array}{l}\text { Afar and Somali pastoral areas of } \\
\text { Eastern Ethiopia }\end{array}$ & 1.9 & 1.7 & 77 \\
\hline Dire Dawa, E/Ethiopia & 9.38 & 9.11 & 78 \\
\hline Pastora area of Oromia and somale & 8.5 & 3.6 & 79 \\
\hline Afar & 9.37 & 4.8 & 49 \\
\hline Arsi and east shoa & 4.6 & 4.61-ELISA & 61 \\
\hline Central and North East Ethiopia & 4.98 & 4.89 & 78 \\
\hline Dire Dawa, E/Ethiopia & 3.5 & 2.6 & 80 \\
\hline Chifra and Ewa districts, Afar & 13 & 12.35 & 68 \\
\hline Borana pastoral system of Ethiopia & 2.0 & 1.6 & 81 \\
\hline
\end{tabular}

using RBPT and CFT, respectively. ${ }^{75}$ Indicated that from a total of 414 serum samples (272 from sheep and 142 from goats) collected from Tellalak district, Afar Region showed 17.7\% tested positive for brucellosis infection by the RBPT and gave 13.7\% counter positive for CFT. In Borena low land the overall sero-prevalence documented by Teshale et $\mathrm{al}^{72}$ revealed that $8.5 \%$ RBPT and $2.3 \%$ C. ELISA. ${ }^{76}$ In Mojo and Debreziet export abattoir indicated that 1.99\% RBPT and 1.6 CFT (Table 1).

From the over study conducted on small ruminant brucellosis in Ethiopia higher sero-prevalence both in RBPT and CFT were seen from lowland area of the countries. Higher prevalence rate $(13.7 \%)$ was found in Afar region where commingling of animals at communal grazing is the common practice. while lower prevalence $0.4 \%$ was recorded in and around Bahir Dar, North West Ethiopia. ${ }^{49}$

\section{CONCLUSION AND RECOMMENDATIONS}

Brucellosis is worldwide and has a high prevalence in different areas of Ethiopia. Brucellosis affects both animals and humans, has a very high economic and public health impact. Its impact on public health is very well related to the infected animal species from which human transmission occurs. The disease is transmitted from infected animals to human beings through several routes. It is a special hazard to occupational groups. It causes considerable losses in small ruminants as a result of abortion and a reduction in milk yield.

Based on the information mentioned conclusion, the following recommendations were forwarded: There should be a strategy to regulate the control mechanism of brucellosis in small ruminants at the national level. Efforts should be made to develop a new vaccine against brucellosis in sheep and goats based on rough strains which are devoid of the disadvantages of the vaccine. The government, public health officers and veterinarians have to work together to reduce the economic and zoonotic impact of brucellosis.

\section{REFERENCES |}

1. Teshome A, Haile G, Nigussie L. Sero-prevalence of small ruminant brucellosis in selected settlements of dire dawa administrative council area, Eastern Ethiopia. Sch. J. Agric. Vet. Sci. 2018; 5(5): 270-276.

2. Ackermann MR, Cheville NF, Deyoe BL. Bovine ileal dome lymphoepithelial cells: Endocytosis and transport of brucella abortus strain 19. Vet. Pathol. 1988; 25: 28-35. doi: $10.1177 / 030098588802500104$

3. Agasthya AS, Isloor S, Krishnamsetty P. Seroprevalence study of human brucellosis by conventional tests and indigenous indirect enzyme linked immunosorbent assay. Sci World J. 2012; 1: 1-3. doi: $10.1100 / 2012 / 104239$

4. Al Dahouk S, Tomaso H, Noockler K, Neubauer H, Frangouli- 
dis D. Laboratory based diagnosis of brucellosis--a review of the literature. Part I: Techniques for direct detection and identifcation of brucella spp. Clin Lab. 2003; 49: 487-505.

5. Alemu Y, Markel RC. Sheep and goat production hand book for Etiopia. Web site. http://www.igadhost.com/igaddata/docs/ Sheep $\% 20$ and $\% 20$ Goat $\% 20$ Production $\% 20$ Hand $\% 20$ Book $\% 20$ for\%20ETHIOPIA.pdf. 2008. Accessed December 24, 2013.

6. Alton GG, Jones LM, Angus RD, Verger JM. Techniques for the Brucellosis Laboratory. Paris, France: Institut National de la Recherche Agronomique; 1988: 190.

7. Alton GG, Jones LM, Peitz DE. Serological Methods. In: Laboratory Techniques in Brucellosis. $2^{\text {nd }}$ ed. WHO, Geneva. 1975: 64-124.

8. Hailu A, Feleke A, Adugna W, Keskes S. Small ruminant brucellosis and public health awareness in two districts of a far region, Ethiopia. Journal of Veterinary Science and Technology. 2016; 7: 335. doi: 10.4172/2157-7579.1000335

9. Araj GF. Update on laboratory diagnosis of human brucellosis. Int J Antimicrob Agents. 2010; 36 Suppl 1: S12-S17. doi: 10.1016/j. ijantimicag.2010.06.014

10. Ashenafi F, Teshale S, Ejeta G, Fikru R, Laikemariam Y. Distribution of brucellosis among small ruminants in pastoral region of a far, Eastern Ethiopia. Rev Sci Tech. 2007; 26(3): 731-739 . doi: $10.20506 /$ rst.26.3.1781

11. Agricultural sample survey (ASS), Federal Democratic Republic Of Ethiopia, Central statistical Agency. Agricultural sample survey. Volume II on livestock and livestock Characteristics. (private peasant holdings). Web site. https://searchworks.stanford.edu/ view/6509594. 2017. 9-20. Accessed December 24, 2013.

12. Aune K, Rhyan JC, Russell R, Roffe TJ, Corso B. Environmental persistence of Brucella abortus in the Greater Yellowstone Area. Journal of Wildlife Management. 2012; 76: 253-261. doi: 10.1002/jwmg. 274

13. Bauerfeind R, Graevenitz A, Kimmig P, et al. Zoonoses: Infectious Diseases Transmissible from Animals and Humans. Washington, DC, USA: ASM Press; 2016: 192-195.

14. Benkirane A. Ovine and caprine brucellosis: World distribution and control/eradication strategies in West Asia/North Africa region. Small Rumin Res. 2006; 62: 19-25. doi: 10.1016/j.smallrumres.2005.07.032

15. Blasco JM. Existing and future vaccines against brucellosis in small ruminants. Small Rumin Res. 2006; 62: 33-37. doi: 10.1016/j. smallrumres.2005.07.034

16. Bricker BJ. Diagnostic strategies used for the identification of Brucella. Vet Microbiol. 2002; 90: 433-434. doi: 10.1016/S03781135(02)00227-4
17. Bruktayet W, Marsha C. Review on cattle brucellosis in Ethiopia. Aca J Animal Dis. 2016; 5: 28-39. doi: 10.5829/idosi.ajad.2016.28.39

18. Carmichael E, Greene E. Canine brucellosis. In: Infectious Diseases of the Dog and Cat. Philadelphia, USA: WB Saunders; 1990: 573-584.

19. The Center for Food Security and Public Health (CFSPH). Brucellosis. Web site. http://www.cfsph.iastate.edu/DiseaseInfo/ disease.php?name=brucellosis-human\&lang=en. 2007. Accessed December 24, 2013

20. Corbel MJ, Brucellosis in Humans and Animals. Geneva, Switzerland: WHO Press; Web site. https://www.who.int/csr/resources/ publications/Brucellosis.pdf. 2006. Accessed December 24, 2013.

21. Central Statistics Authority (CSA). Ethiopian-agricultural-sample-enumeration-200102-1994-ec. Web site. https:// harvestchoice. org/publications/ethiopian-agricultural-sample-enumeration200102-1994-ec-results-country-level-statis-3. Accessed December 24, 2013.

22. Central Statistics Authority (CSA). Estimated Number of Cattle, Sheep and Goats by Regions. CSA, Addis Ababa. 2005.

23. Cutler SJ, Whatmore AM, Commander NJ. Brucellosis new aspects of an old disease. J Appl Microbiol. 2005; 98: 1270-1281. doi: 10.1111/j.1365-2672.2005.02622.x

24. Debassa G, Tefera M, Addis M. Small ruminant brucellosis in yabello district, Ethiopia. Asia Journal of Animal Science. 2013; 7(1): 14-21. doi: 10.3923/ajas.2013.14.21

25. Deddefo A, Sisay T, Tuli G. Seroprevalence and risk factors of small ruminant brucellosis in selected districts of Arsi and East Shoa zones, Oromia region, Ethiopia. African Journal of Microbiology Research. 2015; 9(19): 1338-1344. doi: 10.5897/AJMR2015.7400

26. Food and Agriculture Organization of the United Nations (FAO), World Health Organization (WHO), World Organisation for Animal Health (OIE). Brucellosis in Humans and Animals. 2006.

27. Poester FP, Nielsen K, Samartino LE, Yu WL. Diagnosis of Brucellosis. The Open Veterinary Science Journal. 2010; 4: 46-60. doi: 10.2174/1874318801004010046

28. Franco MP, Mulder M, Gilman RH, Smiths HL. Human brucellosis. Lancet Infect Dis. 2007; 7: 775-786. doi: 10.1016/S14733099(07)70286-4

29. Gall D, Nielsen K, Forbes L, Cook W, Leclair D. Evaluation of the fluorescence polarization assay and comparison to other serological assays for detection of brucellosis in cervids. $J$ Wildl Dis. 2001; 37: 110-118. doi: 10.7589/0090-3558-37.1.110

30. Gall D, Nielsen K, Vigliocco A, Smith P, Perez B. Evaluation of an indirect-linked immunoassay for presumptive serodiagnosis 
of Brucella ovis in sheep. Small Rum Res. 2003; 48: 173-179. doi: 10.1016/S0921-4488(03)00013-0

31. Garin-Bastuji B. Brucella Species. Encyclopaedia of Dairy Sciences. London, England: Academic Press; 2011: 31-39.

32. Garry AL, Christopher JS. Natural resistance against brucellosis. The Open Veterinary Science Journal. 2010; 4: 61-71. doi : 10.2174/1874318801004010061

33. Regassa G. Brucellosis and its control through one health approaches Ethiopia. Journal of Veternary Medicine. 2017; 4(3): 1080.

34. Ghanem YM, El-Khodery SA, Saad AA, Abdelkader AH, Heybe A, Musse YA. Sero prevalence of camel brucellosis (Camelus dromedarius) in Somaliland. Trop Anim Health Prod. 2009; 41(8): 1779-1786. doi: 10.1007/s11250-009-9377-9

35. Glenn JS, Karen WP. Veterinary Microbiology: Bacterial and Fungal Agents of Animal Diseases. Philadelphia, USA: Saunders; 2005. 200203.

36. Gul T, Khan A. Epidemiology and epizootology of brucellosis. Pakistan Vet J. 2007; 27(3): 145-151.

37. Hegazy YM, Moad A, Osman S, Ridler A, Guitian A. Ruminant Brucellosis in the kafr el-sheikh governate of the nile delta, Egypt prevalence of neglected Zoonosis. Plos Negl Trop Dis. 2011; 5:e944. doi: 10.1371/journal.pntd.0000944

38. Interim Brucellosis Manual (IBM). Interim Manual for Brucellosis in Cattle. Department of Agriculture, Fisheries and Forestry, Republic of South Africa. Web site. https://www.nda.agric.za/vetweb/pamphlets\&Information/Policy/Brucellosis $\% 20$ in $\% 20$ Cattle $\% 20$ Interim $\% 20$ Manual $\% 20$ for $\% 20$ the $\% 20$ Veterinarian $\% 20 \% 20 \& \% 20$ AHT\%20-\%20Sept2016_signed.pdf. Accessed December 24, 2013.

39. Ifa N, Shimelis S, Beyene D. Seroprevalence of small ruminant brucellosis and its public health awareness in selected sites of Dire Dawa. Journal of Veterinary Medicine and Animal Health. 2012; 4(4): 61-66.

40. International Committee on Systematics of Prokaryotes (ICSP). Subcommittee on the Taxonomy of Brucella. Web site. https://www.the-icsp.org/taxonomic-subcommittees. Accessed December 24, 2013.

41. International Livestock Research Institute (ILRI), 2006. Domestic Animal Genetic Resource Information System (DAGRIS). Web site. https://www.ilri.org/research/projects/domestic-animal-genetic-resources-information-system-dagris. Accessed December 24, 2013.

42. Jergefa T, Kelay B, Bekana M, Teshale S, Gustafson H, Kindahl H. Epidemiological study of bovine brucellosis in three agroecological areas of central Oromiya, Ethiopia. Rev Sci Tech. 2009;
28(3): 933-943.

43. Lopez-Goni I, Garcia-Yoldi D, Marin M, De-Miguel J, Munoz M. Evaluation of a multiplex PCR assay (Bruce-ladder) for molecular typing of all Brucella species, including the vaccine strains. J Clin Microbiol. 2008; 46: 3484-3487. doi: 10.1128/JCM.00837-08

44. MacMillan A. Conventional serological tests. In: Animal Brucellosis. Florida, USA: CRC Press Inc; 1990: 153-198.

45. Mantur BG, Amarnath SK, Shinde RS. Review of clinical and laboratory features of human brucellosis. Indian J Med Microbiol. 2007; 25: 188-202. doi: 10.4103/0255-0857.34758

46. McDermott JJ, Arimi SM. Brucellosis in sub-Saharan Africa: Epidemiology, control and impact. Vet Microbiol. 2002; 90: 111-134. doi: 10.1016/S0378-1135(02)00249-3

47. Megersa B, Biffa D, Abunna F, Regassa A, Godfroid J, Skjerve E. Sero epidemiological study of livestock brucellosis in a pastoral region. Epidemiol Infect. 2012; 140: 887-896. doi: 10.1017/ S0950268811001178

48. Miguel JD, Marín CM, Mun PM, Diesteoz L, Grillo MJ, Blasco JM. Development of a selective culture medium for primary isolation of the main Brucella species. J Clin Microbiol. 2011; 49: 14581463. doi: 10.1128/JCM.02301-10

49. Ministry of Agriculture and Rural Development (MoARD). Livestock development master plan study. Web site. http://www. igadhost.com/igaddata/docs/LDMPS_Phase\%20I_Vol.K_ Hides\%20\&\%20Skins.pdf. Accessed December 24, 2013.

50. Mohammed M, Mindaye S, Hailemariam Z, Tamerat N, Muktar Y. Sero prevalence of small ruminant brucellosis in tree selected districts of somali region, Eastern Ethiopia. Journal of Vet Sci Anim Husb. 2017; 5(1): 105. doi: 10.15744/2348-9790.5.105

51. Morata P, Queipo-Ortuno MI, Rugvera MI, Garcia-Ordonez MA, Cardenas A, Colmenero JD. Development and evaluation of a PCR-Enzyme-linked immunosorbent assay for diagnosis of human brucellosis. J Clin Microbiol. 2003; 41: 144-148. doi: 10.1128/ JCM.41.1.144-148.2003

52. Nielsen K, Dunkan JR. Animal Brucellosis. Florida, USA: CRS Press INC; 1990: 173-179.

53. Nielsen K, Gall D, Smith P, Balsevicius S, Garrido F. Comparison of serological tests for the detection of ovine and caprine antibody to Brucella melitensis. Rev Sci Tech. 2004; 23: 979-987. doi: $10.20506 /$ rst.23.3.1532

54. Office of International de Epizootics (OIE). Ovine epididymitis (B.ovis) in terrestrial. Web site. http://www.oie.int/. Accessed December 24, 2014.

55. Office International Des Epizooties (OIE). Manual of Standards 
for Diagnostic Tests and Vaccines. $4^{\text {th }}$ ed. Paris, France. 2000; 475-481.

56. Pappas G, Panagopoulou P, Christou L, Akritidis N. Brucella as a biological weapon. Cell Mol Life Sci. 2006; 63: 2229-2236. doi : 10.1007/s00018-006-6311-4

57. Perrett LL, McGiven JA, Brew SD, Stack JA. Evaluation ofcompetitive ELISA for detection of antibodies to Brucella infection indomestic animals. Croat Med J. 2010; 51: 314-319. doi: 10.3325/cmj.2010.51.314

58. Poester P, Nielsen K, Samartino E. Diagnosis of brucellosis. Open Vet Sci J. 2010; 4: 46-60. doi: 10.2174/1874318801004010046

59. Quinn PJ, Carter ME, Markey B, Carter GR. Clinical Veterinary Microbiology. $1^{\text {st }}$ ed. Missouri, USA: Mosby; 1993: 261-267.

60. Quinn PJ, Markey BK, Carter ME, Donnelly WJC, Leonard FC, Maguire D. Brucella Species. In: Veterinary Microbiology and Microbial Disease. London, UK: Wiley-Blackwell; 2002: 999-1000.

61. Radostits ED, Gay CC, Inchcliff WK. Veterinary Medicine, Textbook of the Diseases of Cattle, Sheep, Pigs, Goats and Horses. $9^{\text {th }}$ ed. New York, USA: Saunders Ltd; 2000: 867-882.

62. Radostits ED, Gay CC, Inchcliff WK. Veterinary Medicine, Textbook of the Diseases of Cattle, Sheep, Pigs, Goats and Horses. $10^{\text {th }} \mathrm{ed}$. ELBS Bailliere Tindall, London, UK: Saunders Ltd; 2007: 963-994.

63. Redkar R, Rose S, Bricker B, DelVecchio V. Real-time detection of Brucella abortus, Brucella melitensis and Brucella suis. Mol Cell Probes. 2001; 15: 43-52. doi: 10.1006/mcpr.2000.0338

64. Robles CA, Uzal FA, Olaechea FV. Epidemiological observations in a Corriedale flock affected by B.ovis. Vet. Res. Commun. 1998; 22: 435-443. doi: 10.1023/a:1006158514414

65. Sam IC1, Karunakaran R, Kamarulzaman A, et al. A large exposure to Brucella melitensis in a diagnostic laboratory. J Hosp Infect. 2012; 80(4): 321-325. doi: 10.1016/j.jhin.2011.12.004

66. Sathyanarayan S, Suresh S, Krishna S, Mariraj J. A comparative study of agglutination tests, blood culture and ELISA in the laboratory diagnosis of human brucellosis. Int J Biol Med Res. 2011; 2: 569-572.

67. Scholz HC, Revilla-Fernández S, Al Dahouk S, et al. BrucellaVulpis spp.nov, isolated from mandibulara lymph nodes of red fox. Int J Syst Evol Microbiol. 2016; 66(5): 2090-2098. doi: 10.1099/ ijsem.0.000998

68. Schwarz HJ, Dioli M. The One Humped Camel in Eastern Africa. A Practical Guide to Disease Health Care and Management. Weikersheim, Germany: Verlag Josef Margraf; 1992: 1-230.

69. Seifert SH. Tropical Animal Health. $2^{\text {nd }}$ ed. Dordrecht, the Netherlands: Kluwer Academic; 1996: 356-367.
70. Nigatu S, Deneke M, Kassa T. Sero-prevalence of Brucellosis in sheep and goat destined for slaughter in selected export abattoirs, Ethiopia. African Journal of Basic \& Applied Sciences. 2014; 6(3): 82-86. doi: 10.5829/idosi.ajbas.2014.6.3.8638

71. Addis SA, Desalegn AY. Comparative sero epidemiological study of Brucellosis in sheep under smallholder farming and governmental breeding ranches of central and North East Ethiopia. J Vet Med. 2018; 2018: 7239156. doi: 10.1155/2018/7239156

72. Teshale S, Muhie Y, Dagne A, Kidanemariam A. Seroprevalence of small ruminant brucellosis in selected districts of Afar and Somali pastoral areas of Eastern Ethiopia: The impact of husbandry practice. Revue Méd.Vét. 2006; 157: 557-563.

73. Tewodros AE, Dawit AA. Sero-prevalence of small ruminant Brucellosis in and around Kombolcha, North-Eastern Ethiopia.J Vet Sci Med Diagn. 2015; 4: 286-291. doi: 10.4172/23259590.1000173

74. Tigist A, Yosefe D, Tadele T. Seroprevalence of caprine brucellosis and associated risk factors in South Omo Zone of Southern Ethiopia. African Journal of Microbiology Research. 2011; 5(13): 16821686. doi: 10.5897/AJMR11.377

75. Tsegay A, Kassa T, Kebede N. Seroprevalence and risk factors of Brucellosis in small ruminants slaughtered at Debre Ziet and Modjo export abattoirs, Ethiopia. J Infect Dev Ctries. 2015; 9(4): 373-380. doi: $10.3855 /$ jidc.4993

76. Tsehay H, Getachew G, Morka A, Tadesse B, Eyob H. Sero prevalence of small ruminant brucellosis in pastoral area of Oromia and Somale regional state. J Vet Med Anim Health. 2014; 6(11): 289-294. doi: 10.5897/JVMAH2014.0331

77. Wadood F, Ahmad M, Khan A, Gul ST, Rehman N. Seroprevalence of Brucellosis in horses in and around Faisalabad. Pakistan Vet J. 2009; 29(4): 196-198.

78. Wedejo MT, Fekadu RG, Tefera YM, Yalew TA, Alemayehu LB, Abdi AD. Seroprevalance of small ruminant brucellosis and its effect on production at Tellalek district, Afar. J Vet Med Anim Health. 2015.

79. Wernery U, Kaaden OR. Infectious Disease of Camelides. London, UK: Black well Science Inc; 2002: 99-116.

80. World Health Organization (WHO). Brucellosis in human and animals. Web site. https://www.who.int/csr/resources/publications/Brucellosis.pdf. Accessed December 24, 2013.

81. Zewdie W. Small ruminant brucellosis and awareness of pastoralist community about zoonotic importance of the disease in Yabello districts of Borena Zone Oromia regional state, S/Ethiopia. Curr Trends Biomedical Eng \& Biosci. 2018; 12(1). doi: 10.19080/ CTBEB.2018.12.555827 